\title{
Predictibility and aesthetics in the anterior sector
}

\section{Previsibilidad y estética en el sector anterior}

\author{
OROZCO-RODRIGUEZ, Rubén, ROSADO-VILA, Graciella, ZAPATA-MAY, Rafael and PINZON- \\ SIERRA, Patricia
}

Universidad Autonoma de Campeche, Faculty of Odontology and Faculty of Nursing, San Francisco de Campeche, México

ID $1^{\text {st }}$ Author: Ruben, Orozco-Rodriguez / ORCID 0000-0002-5425-0107

ID $1^{\text {st }}$ Coauthor: Graciella, Rosado-Vila / ORC ID 0000-0002-8688

ID $2^{\text {nd }}$ Coauthor: Rafael, Zapata-May / ORCID 0000-0002-3750

ID $3^{\text {rd }}$ Coauthor: Patricia, Pinzon-Sierra / ORCID 0000-0001-7842-9841

Received: September 09, 2019; Accepted: December 30, 2019

\begin{abstract}
Introduction: Today the aesthetic demand in dentistry occupies the first places in terms of consultation needs in the dental office, that is why, as providers of dental health services, we are obliged to offer treatment options that meet standards of quality, functionality, aesthetics, predictability among other things and that are available to different social levels4. There are techniques that supported by elements such as Digital Smile Design (DSD) 9, wax up and mockup5 offer excellent, predictable aesthetic results, with the option of choosing different materials that are available to all our patients from composite resin to better than we find today; the porcelain clinical case: A 25-year-old female patient who goes to a dental office for teeth whitening, when diagnosing the case, the presence of diastema was observed in the upper centers, as well as anomalies regarding aesthetic smile parameters such as pigmentation, proportions, incisal edge line, among other things. Diagnostic waxing, mockup and photographs were performed to evaluate the result. The treatment plan consisted of 6 resin veneers made with the fluid resin injection technique through a transparent silicone matrix (Flow injection technique). RESULTS: The prognosis of the case is considered favorable, taking into account that the treatment with Resins is not definitive, however functional and aesthetic results were achieved properly. Conclusions: There are several treatment alternatives for the solution of aesthetic problems, which adapt to the possibilities of each patient, the mockup is a necessary tool for obtaining predictable treatments. The fluid resin injection technique is a good aesthetic and functional treatment, which sometimes does not require the minimum wear of the teeth to be treated.
\end{abstract}

Dental prosthesis, Oral health, Aesthetics

\section{Resumen}

Introducción: Hoy en día la demanda estética en odontología ocupa los primeros lugares en cuanto a necesidades de consulta en el consultorio dental, por lo que, como prestadores de servicios de salud dental, estamos obligados a ofrecer opciones de tratamiento que reúnan estándares de calidad, funcionalidad, estética, predictibilidad entre otras cosas y que estén al alcance de los distintos niveles sociales ${ }^{4}$. Existen técnicas que apoyadas por elementos como el Diseño Digital de Sonrisa (DSD) ${ }^{9}$, el wax up y el mockup ${ }^{5}$ ofrecen excelentes resultados estéticos predecibles, con la opción de elegir distintos materiales que estén al alcance de todos nuestros pacientes desde resina compuesta hasta lo mejor que encontramos hoy en día; la porcelana. Caso clínico: Paciente femenina de 25 años que acude a consulta odontológica por blanqueamiento dental, al realizar el diagnóstico del caso se observó la presencia de diastema en los centrales superiores, así como anomalías en cuanto a parámetros de sonrisa estéticos: como pigmentaciones, proporciones, línea del borde incisal, entre otras cosas. Se realizó encerado de diagnóstico, mockup y fotografías para evaluar el resultado. El plan de tratamiento constó de 6 carillas de resina, elaboradas con la técnica de inyección de resina fluida a través de una matriz de silicona transparente (Flow injection technique). Resultados: El pronóstico del caso se considera favorable, tomando en cuenta que el tratamiento con resinas no es definitivo, sin embargo los resultados funcionales y estéticos se lograron obtener adecuadamente. Conclusiones: el mockup es una herramienta necesaria para la obtención de tratamientos predecibles. La técnica de inyección de resina fluida es una buen tratamiento estético y funcional, que en ocasiones no requiere desgaste de los dientes a tratar.

Protesis dental, Salud oral, Estética

Citation: OROZCO-RODRIGUEZ, Rubén, ROSADO-VILA, Graciella, ZAPATA-MAY, Rafael and PINZON-SIERRA, Patricia. Predictibility and aesthetics in the anterior sector. ECORFAN Journal-Bolivia. 2019. 6-11: 30-34

$\dagger$ Researcher contributing as first author. 


\section{Introduction}

The word aesthetic comes from the Greek

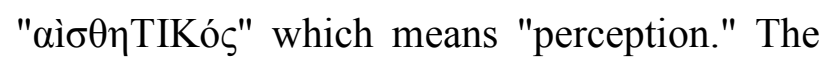
term aesthetics from an etymological point of view means, relative to a state of "sensitive" esthesia as the "no sensitivity" anesthesia counterpart. At present the term has been used as a study of beauty and its opposite ugliness ${ }^{3}$. Some authors mention that beauty can be divided into two dimensions: objective (admirable) and subjective (pleasant) beauty. Objective beauty implies that the object possesses properties that make it evidently commendable. Subjective beauty is loaded with value and is related to the tastes of the person who contemplates it. "Contemporary dentistry techniques should help objective aesthetics for the orofacial complex, encompassing coherence, shape, structure, balance, color, function and dental exposure. You might think that the search for these aesthetic characteristics in the position of this or that dental organ is to look for characteristics of that objective "beauty"3.

Today the aesthetic demand in dentistry occupies the first places in terms of consultation needs in the dental office, so, as providers of dental health services, we are obliged to offer treatment options that meet quality standards, functionality, aesthetics, predictability among other things and that are within reach of different social levels. Currently there are different options in terms of materials to offer our patients, there is no doubt that porcelain is a material for the rehabilitation of teeth that has advantages over others, but its Achilles heel is located in the cost as it remains high above compared to others such as composite resin, with which we can obtain excellent results if your treatment protocol is adequate; and in this way expand the range of possibilities to offer for our treatments and that are available to all people ${ }^{4,2}$. The composite resin has been positioned as one of the materials of choice not only as a direct restoration material, in cases of dental surgery or reconstruction of teeth with root canal treatment, but also for its improved qualities over the years today Its use includes aesthetic functional prototypes and transient smile designs whose varied techniques for its realization have achieved very favorable results. ${ }^{6,7}$
At present, the use and use of auxiliaries is of paramount importance so that our treatments are predictable and thus be able to convince us of their reliability. The digital smile design (DSD) is a digital planning tool for aesthetic dentistry, in which the evaluation of the aesthetic relationship between teeth, gum, smile and face is obtained through digital lines and drawings that they are inserted in the patient's facial and intraoral photographs. The use of digital tools offers dentists and technicians a new perspective for diagnosis and treatment plan, facilitating and improving communication between the dentist, the technician and the patient9. Other auxiliary and no less important elements are wax up and mock up; The first is to develop an aesthetic solution from a plaster model of the patient using laboratory wax. However, aesthetic and functional benefits are limited.

From the aesthetic point of view, the wax allows to visualize the shape and position of the teeth in the planned restoration, but does not reproduce exactly the color and function of the teeth, for this it is necessary that the mock up comes into play, This is a preview model made with materials such as acrylic resin or composite resin. This technique allows a preview of the aesthetic result and, thus, plays an important role in the planning of treatment. The mock-up constitutes the phase after the waxing validation. In this step, the restoration model, previously validated in the plaster model, is adjusted in the patient's mouth. In this way, the waxing information can be transferred directly from the patient's model to the mouth. The "test" in the patient's mouth can be checked for aesthetic, functional and psychological aspects of the restoration. This last point is decisive in providing an important concept for patient acceptance. ${ }^{5}$.

The injected fluid resin technique is a novel direct / indirect process that allows us to foreseeably reproduce a diagnostic waxing with composite resin restorations, by injecting it into the patient's natural teeth through a transparent silicone matrix. Clinical applications include emergency repair of fractured teeth and restorations, fabrication of provisional restorations, composite transition restorations (class III, IV, veneers) 
And pediatric composite crowns, reconstruction of occlusal wear in posterior composite restorations, establishment of edge length incisal before the aesthetic lengthening of the crown and the development of compound prototypes for milling. In addition, this technique can be used to establish the vertical dimension and to alter the occlusal schemes (anterior guide and posterior deocclusion) before obtaining the final restorations. It is a non-invasive technique that is also used to improve communication between the patient and the restorative team during treatment planning. ${ }^{1}$. The objective of this work is to demonstrate that the fluid resin injection technique is a good procedure that, supported by tools such as mock up, gives us excellent aesthetic and functional results.

\section{Presentation of the case}

25-year-old female patient who goes to dental consultation for teeth whitening, when diagnosing the case, the presence of diastema was observed in the upper centrals, as well as anomalies regarding aesthetic smile parameters such as pigmentation, proportions, incisal edge line, among other things. Diagnostic waxing, mockup and photographs were performed to evaluate the result. The treatment plan consisted of 6 resin veneers made with the fluid resin injection technique through a transparent silicone matrix (Flow injection technique).

\section{Clinical procedure}

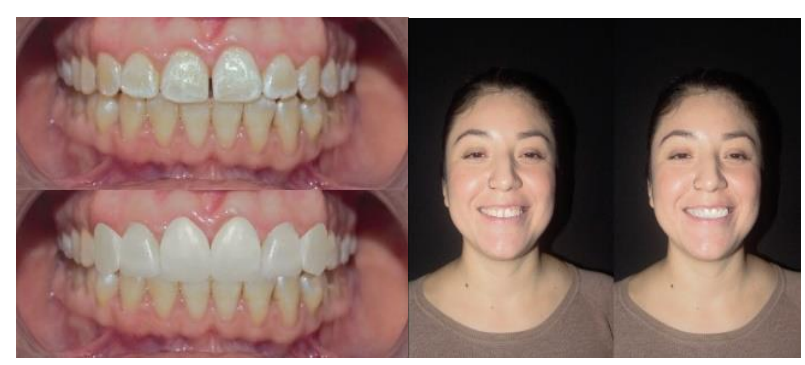

Figure 1 DSD

Source: Self Made

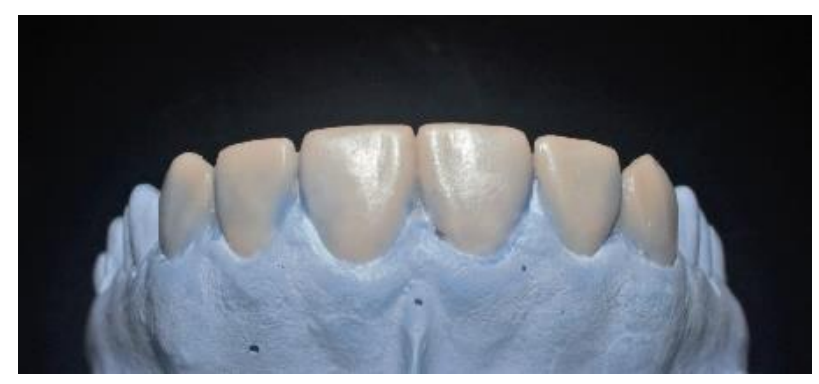

Figure 2 Diagnostic Waxing

Source: Self Made

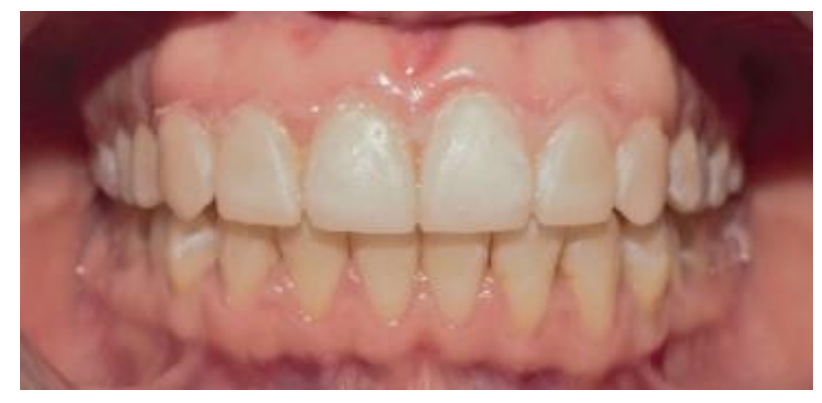

Figure 3

Source: Self Made

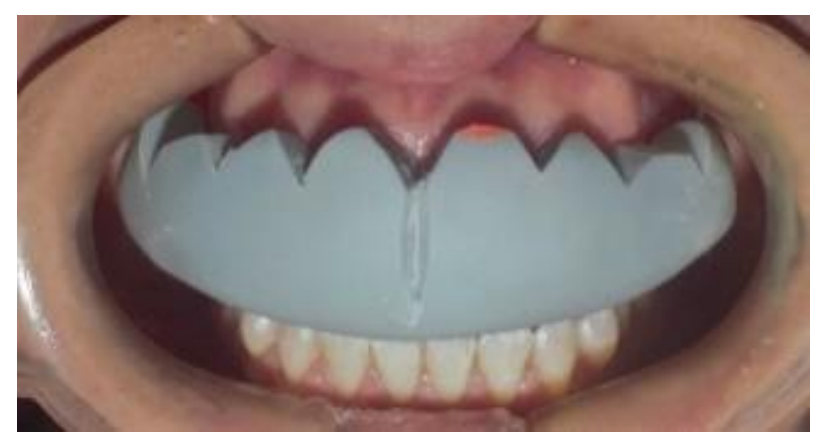

Figure 4

Source: Self Made

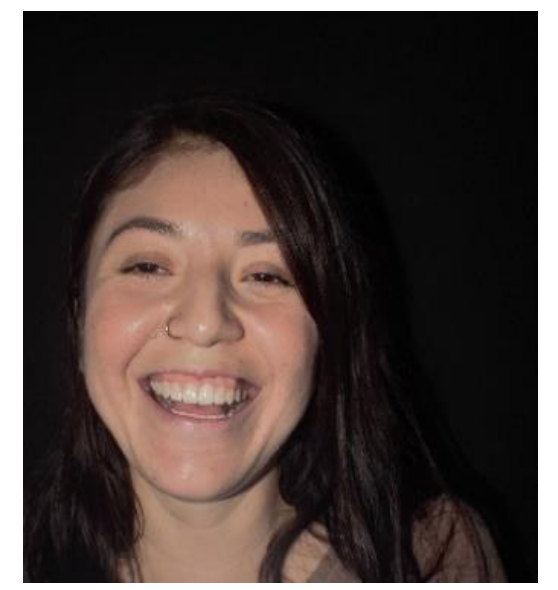

Figure 5 Mockup analysis

Source: Self Made
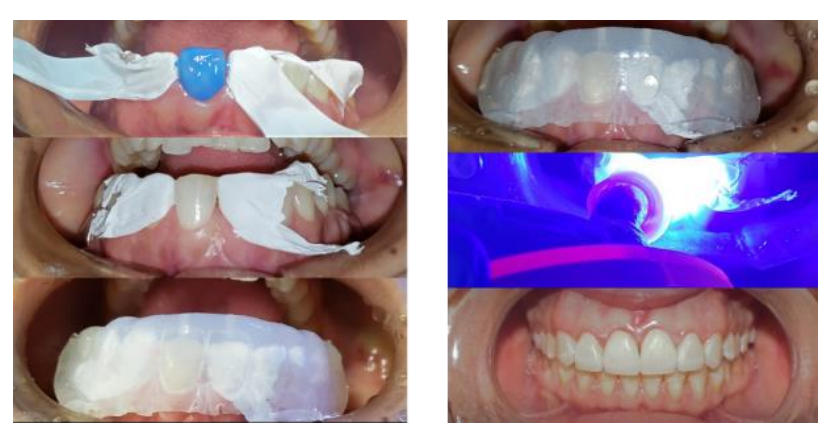

Figure 6 Procedure

Source: Self Made 


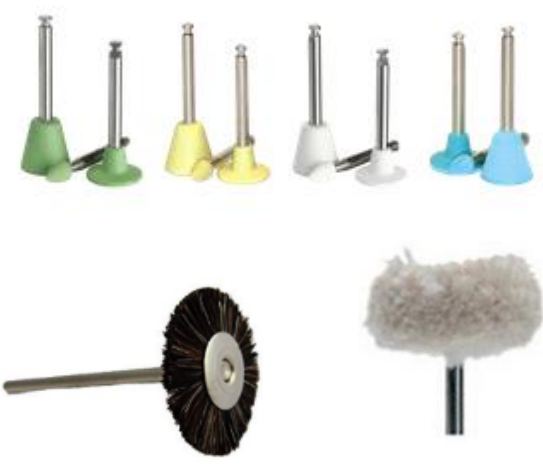

Figure 7 Polishing system Source: Self Made

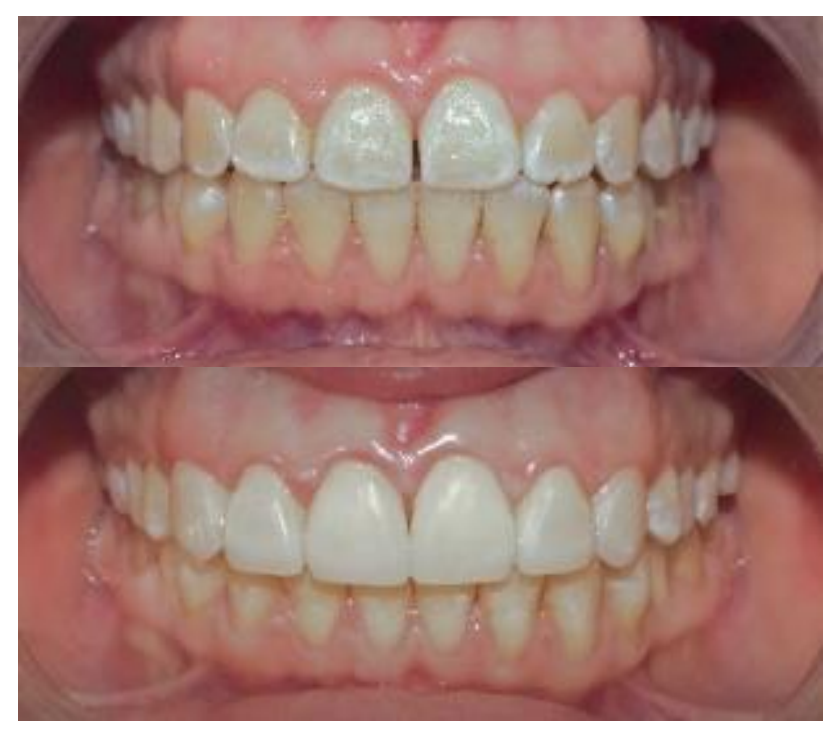

Figure 8 Before and After Source: Self Made

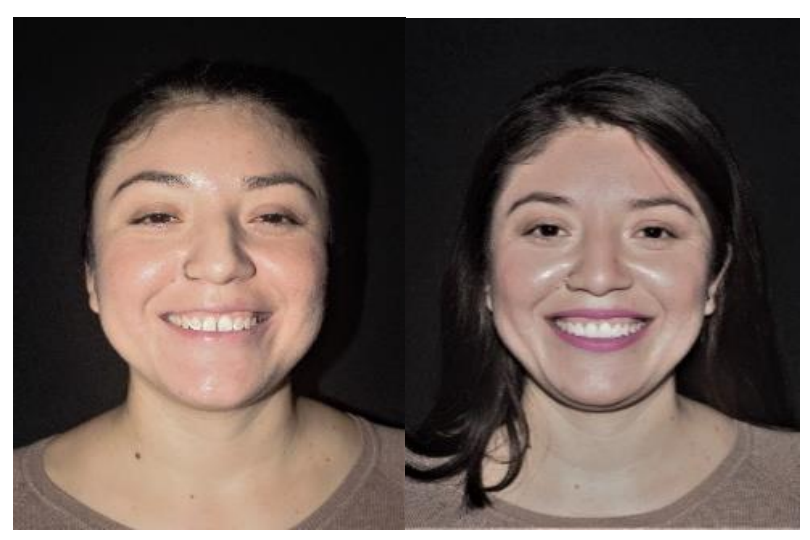

Figure 9 Before and After Source: Self Made

Study models, photographs, prior anamnesis and clinical history filling were made, diagnostic waxing was obtained with additive technique (Renfert modeling wax) for which the obtained DSD (Img. 1 and 2) was taken as a reference, it was used PK Thomas hand instrument.
The result was subsequently proposed to the patient by means of a mock up (Img. 3 polymethyl siloxane and acrylic resin) with which the situation at the mouth of what was obtained in the waxing was analyzed (Img. 4 and 5)

We proceed to perform the fluid resin injection technique for which a transparent polyvinyl siloxane silicone matrix (Memosil 2) was obtained from the diagnostic waxing, which was made holes with round milling cutter of carbide number 8 and micromotor in the area of incisal edges of the teeth 13 to 23 , the surpluses were cleaned with alcohol, each tooth was isolated from its adjacent ones with Teflon tape, the preparation of the dental substrate was carried out: total etching (ultra etch phosphoric acid 35\%), washing, adhesive placement (Peak universal bond) and light-curing for 20 seconds with bluephase lamp (ivoclar vivadent).

Once the process was finished, the transparent silicone matrix was brought to the mouth and fluid resin (tetric N Flow color bleach) was injected through the previously made hole, light-cured, and after removal of the matrix, excess surpluses were removed. resin with a scalpel blade (no. 12). The same procedure was applied for each tooth (Img 6). To finish the polishing of the veneers was carried out by means of rubber cups of thick, medium and fine grain respectively (jiffy) and was finished with horse hair and cotton tassel, all this with a low speed engine at 10,000 rpm. (Img. 7).

\section{Results}

The prognosis of the case is considered favorable, taking into account that the resin treatment is not definitive, however, the functional and aesthetic results were obtained properly (Img. 8 and 9).

\section{Conclusions}

Mock up is a necessary tool for obtaining predictable treatments, it allows us to preview the treatment plan and its aesthetic and functional analysis5. The fluid resin injection technique is a minimally invasive technique through which we obtain aesthetic and functional treatments, its greatest disadvantage is its durability since it is not considered a definitive treatment 1 . 
It is possible to perform aesthetic and functional treatments with cheaper materials than porcelain, such is the case of composite resin.

\section{References}

[1]Terry D, Powers J. (2015) Using injectable resin composite: part one, INTERNATIONAL DENTISTRY-AFRICAN EDITION, VOL. 5 NO. 1, pgs. 52-62.

[2]Alothman Y, Saleh M. (2018) The succes of Dental Veneers According To Preparation Design and Material Type, Journal of Medical Science.

[3]Orr C. (2016) 'State of the art' in aesthetic dentistry, British Dental Journal, Volume 221 No. 8.

[4]Cohelo F, Silveira D, Peres Michele, y col. (2015). Direct anterior composite veneres in vital and not vital teeth, Journal of Dentistry, Elsevier, Brazil.

[5]Yassine H. (2016) El Mockup, Dental Tribune Hispanic and Latin America.

[6]Lamas C, Angulo de la Vega G. Reconstrucción del Sector Anterior con resinas compuestas, Odontol. G. (2016). La supervivencia de las restauraciones directas de composite en el manejo del desgaste dental severo que incluye desgaste y erosión: un estudio prospectivo de 8 años. Jornal of Dentistry, Elsevier.

[7]Orozco J, Berrocal J, Diaz A. (2015). Composite veneers as an alternative to ceramic veneers in the treatment of dental anomalies. Case report. Revista clínica de periodoncia, implantología y rehabilitación oral.

[8]Pontes P, Goulart da Costa R, Clagaro M, y col. (2018) Diseño de sonrisa digital y técnica de maqueta para la planificación del tratamiento estético con carillas de porcelana laminada, Journal of conservative dentistry.

[9]Terry D, Powers J. Using injectable resin composite, part two.

http://www.moderndentistrymedia.com/jan_feb 2015/terr_part-two.pdf.
[10]Eng E, Jorge Ulloa. (2019) Dental Veneers with injectable composite resine technique. Case Report. Revista Científica Universitaria de las Ciencias d 